\title{
Effects of different maturity stages on antioxidant attributes of indian gooseberry (Phyllanthus emblica L.)
}

\author{
Kalaskar Mohan G1,", Bagul Vishal S. ${ }^{2}$, Tatiya Anil U. ${ }^{3}$, Chalikwar Shailesh S., , Surana Saniav J. ${ }^{5}$ \\ ${ }^{\mathbf{1}}$ Associate Professor, ${ }^{\mathbf{2}}$ Research Scholar, ${ }^{3-5}$ Professor, Dept. of Pharmacognosy, R. C. Patel Institute of Pharmaceutical Education \\ and Research, Shirpur, Dist. Dhule, Maharashtra, India
}

*Corresponding Author:

Email: kalaskar.mohan@gmail.com

\begin{abstract}
Amla is Indian traditional medicinal plant with diverse and potent therapeutic potential. The present investigation was carried out to evaluate the levels of total polyphenols as well as antioxidant potential at three different ripening stages (un-ripe, semi-ripe and fully-ripe) of amla (Phyllanthus emblica L.) fruit. The antioxidant ability of amla fruit extract was assessed by using in-vitro antioxidant assays that are DPPH, ABTS scavenging assay and total antioxidant capacity. Overall, fruit at the fully mature stage (S3) exhibited the highest levels of TPC, TFC, ABTS, DPPH and radical scavenging activity and total antioxidant capacity, followed by the intermediate (S2) and immature (S1) stages. The results showed that different stages of maturation had profound effects on the antioxidant activity of amla fruit.
\end{abstract}

Keyword: Amla, Antioxidant, Total phenolic and flavonoid, Immature, Intermediate and mature.

\section{Introduction}

In the traditional system of medicine, the fruits are widely used for their therapeutic effectiveness in disease conditions such as diabetes, cancer, inflammation and many more through antioxidant mechanism.

It has been established relation between oxidative stress in the pathogenesis of several human diseases, including inflammation, metabolic disorders, cellular aging, cardiovascular diseases, diabetes mellitus, neurodegenerative diseases, cancer and HIV/AIDS. ${ }^{1}$ The edible fruits are rich source of antioxidant phytochemicals especially, phenolic, flavonoid, caretonoids and vitamins. ${ }^{2}$

Recently, there has been an upsurge of interest in the therapeutic potentials of medicinal plants as antiinflammatory, digestive, antinecrotic, neuroprotective, and hepatoprotective agents, with antioxidant and/or radical-scavenging mechanisms partially responsible for these activities. ${ }^{3}$

The content of phytochemicals and the antioxidant capacity of fruits are influenced by numerous factors such as sunlight, soils, season, region of cultivation, fruit variety, and stages of maturity. ${ }^{4-6}$

The maturity stage is an important factor that influences the compositional quality and the quantity of fruits. Due to the fact that during maturation, several variations (biochemical, physiological and structural) take place and determine the fruit's quality. $^{7}$

Antioxidant principles from natural sources provide enormous scope for correcting imbalances between oxidant production and antioxidant defenses. Among these is P. emblica L. (amla), a traditional
Indian medicinal plant used as rasayana and can confer health benefits.

Amla (Phyllanthus emblica L.) belongs to family Euphorbiaceae, commonly used in Indian systems of medicine, is a nutritiously rich food with high therapeutic value.

It has been documented as fruit containing highest amount of vitamin $\mathrm{C}$, which is resistant to storage and heating. Amla is one of the most popular drugs in Ayurvedic and Unani systems of medicine and is one of the major ingredients of Chyawanprash, Triphala, Itrifals and Khamiras. ${ }^{8}$ It is traditionally used to enhance digestion, treat constipation, reduce fever, reduce cough, alleviate asthma, stimulate hair growth, enliven the body, and enhance intellect. Literature survey revealed various pharmacological activities of amla fruits such as antinociceptive, antimicrobial, antioxidant, gastroprotective, hepatoprotective, antiulcerogenic, antidiabetic, antitumor, antiinflammatory, antipyretic and analgesic. ${ }^{9}$

The drug is well known for its antioxidant properties due to presence of ascorbic acid and various phenolic constituents, therefore the change in phytochemistry of plant can be assessed by evaluating its antioxidant potential. The assay for the total phenolic content was carried out along with in-vitro antioxidant activity by using 2, 2-diphenyl-1picrylhydrazyl (DPPH) and ABTS radical scavenging methods and total antioxidant capacity. The present research work will be helpful and serve as an important tool for the quality assessment of the amla. Studies to establish stages of maturity and change in antioxidant potential of amla were limited, so the present study was undertaken to establish stages of maturity and change in antioxidant potential of amla. 


\section{Materials and Method}

Sample collection, preparation and extraction: Fruits of Phyllanthus emblica L. were harvested from Shirpur region during November to December 2016. Amla fruits were picked at three different stages of ripening according to external color; (S1) green were chosen as immature stage greenish yellow were chosen as as the intermediate stage (S2) and yellow to coppery brown as the last stage of maturity (mature stage) (S3). Fruits were made slices and air-dried at room temperature followed by size reduction.

The powder was extracted by maceration with $80 \% \mathrm{MeOH}$ at room temperature and stirred occasionally for 3 days. Then a Whatman No. 1 filter paper was used to remove the particles. The residue was more time extracted, filtered and concentrated using a rotary evaporator (BUCHI, Rotavapor R- 215) under reduced pressure. The dry extract obtained with each solvent was weighed and percentage yield was expressed in terms of air dried weight of plant material.

Qualitative phytochemical investigation: Freshly prepared $P$. emblica fruit extract was subjected to standard phytochemical analysis to ensure the presence of alkaloids, flavonoids, steroids, terpenoids, reducing sugars, tannins, saponins, glycosides, aleurone grains, and proteins. ${ }^{10,11}$

Determination of total phenolics: Total phenolics were determined by the spectrophotometric method with slight modification. ${ }^{12}$ In brief, a $0.1 \mathrm{ml}$ of appropriately diluted extracts was added to $0.2 \mathrm{ml}$ of 10 -fold diluted Folin- Ciocalteau reagent. $2.0 \mathrm{ml}$ of $15 \%$ sodium carbonate was added to mixture and then shaken. After $2 \mathrm{~h}$ incubation period, the absorbance of the reaction mixtures was measured at $760 \mathrm{~nm}$. The standard curve for total phenolics was plotted using gallic acid standard solution $(10-100 \mu \mathrm{g} / \mathrm{ml})$ following the same procedure as mentioned above. The total phenolics were expressed as milligram of gallic acid equivalents (GAE) per gram of dried extract.

DPPH radical-scavenging activity: The radical scavenging activity of different maturity stages of $P$. emblica fruit extract was estimated using stable free radical of 1, 1-diphenyl-2-picrylhydrazyl assay (DPPH). concentrations of each extracts were added, to an equal volume, methanolic DPPH $(100 \mathrm{mM})$ solution. Each of the extract or the reference standard solution was added separately in wells of the microtitre plate and allowed to incubate at room temperature for $20 \mathrm{~min}$. The absorbance of the resulting mixture was measured at $517 \mathrm{~nm}$ against methanol as blank by using using Microplate spectrophotometer (BIO-Tek, USA. Model-96 well micro plate). Known antioxidant such as ascorbic acid was used as positive control. ${ }^{13}$ The percentage of radical scavenging activity was calculated using the formula.
$\%$ inhibition

$=\frac{[(\text { Control absorbance }- \text { Sample absorbance })}{\text { Decrease in the absorbance of the DPPH mixture }} \times 100$ indicates an increase in radical scavenging activity of sample extracts.

ABTS radical cation scavenging activity: ABTS radical cation scavenging activity was performed using the method reported ${ }^{14}$ with slight modifications. In brief, ABTS solution $(7 \mathrm{mM})$ was reacted with potassium persulfate $(2.45 \mathrm{mM})$ solution and kept overnight in the dark to yield a dark colored solution containing ABTS. ${ }^{+}$radical cation. Prior to use in the assay, the ABTS radical cation was diluted with 50\% methanol for an initial absorbance of about 0.700 at $734 \mathrm{~nm}$. After the addition of $1.0 \mathrm{ml}$ of diluted ABTS ${ }^{+}$to $10 \mu l$ of sample, the absorbance was measured after $5 \mathrm{~min}$ of initial mixing. The percentage inhibition was calculated according to the formula:

$\%$ inhibition

$=\frac{[(\text { Control absorbance }- \text { Sample absorbance })}{\text { Control absorbance }} \times 100$

The antioxidant potential of extract was expressed as $\mathrm{IC}_{50}$, the concentration necessary for a $50 \%$ reduction of ABTS $\cdot{ }^{+}$radicals.

Total antioxidant capacity by phosphomolybdenum method: The total antioxidant capacity of Amla extracts were evaluated as reported. ${ }^{12}$ An aliquot of $100 \mu \mathrm{l}$ of extract solutions was combined with $1 \mathrm{ml}$ of reagent $(0.6 \mathrm{M}$ sulfuric acid, $28 \mathrm{mM}$ sodium phosphate and $4 \mathrm{mM}$ ammonium molybdate). All tubes were capped and incubated in a boiling water bath at $95^{\circ} \mathrm{C}$ for $90 \mathrm{~min}$. Tubes were allowed to cool at room temperature. Absorbance of the test and standard solutions was measured at $695 \mathrm{~nm}$ against blank containing $0.1 \mathrm{ml}$ of distilled water and $1 \mathrm{ml}$ of reagent. The standard curve for total antioxidant capacity was plotted using ascorbic acid standard solution $(20-100 \mu \mathrm{g} / \mathrm{ml})$ following after said procedure. An antioxidant capacity was expressed as millimolar equivalents of ascorbic acid.

\section{Results and Discussion}

Percentage Yield of Antioxidant Components from amla Fruit: The results of \% extractive value of three distinct maturity phases of amla fruits revealed as the maturity progressed the $80 \%$ methanol extracts increased. The unripe amla fruits showed lowest extractives compared to fully ripen fruits. The antioxidant components are generally polar in nature so it is recommended to use polar solvents for extraction of antioxidants. ${ }^{15}$ Methanol or watermethanol solvents are used for extraction of antioxidant compounds. ${ }^{16}$ In present study, the fully ripen fruits yields highest extractable compounds 
indicates the accumulation of higher amount of antioxidant compounds (Table 1).

During the transformation of immature to fully mature stages of fruit a series of complex biochemical reactions takes place. This results in qualitative and quantitative variation in the composition of phytochemicals such as phenolics, anthocyanins, carotenoids and other volatile compounds leading to the development of final characteristics and distinctcolor, flavour and texture of a mature fruit. ${ }^{17,18}$

Total phenolic content: Folin-Ciocalteu method was used for determination of total phenolic content of amla extracts. This reagent preferably react with phenolic compounds by forming complex between phenolic compounds and phosphomolybdic tungstate results in change in color from yellow to blue which can be quantitatively measured at $755 \mathrm{~nm}$. In the present study, the content of phenolic compounds has varied significantly during fruit maturation and found in order of S3>S2>S1 (Table 1). Generally, the TPC found to be higher in immature condition than fully ripen one, as there is a loss in astringency during ripening, which may be associated with an increase in polyphenol oxidase activity and polymerization of leucoanthocyanidins and hydrolysis of the astringent principle. ${ }^{19,20}$ In present study, the TPC is higher in mature fruit extract $(105.3 \pm 0.34 \mathrm{mg} / \mathrm{gm}$ GAE $)$ than immature $(78.5 \pm 0.22 \mathrm{mg} / \mathrm{gm} \mathrm{GAE})$, it might be accumulation of higher amount of vitamin $\mathrm{C}$ and $\mathrm{Cu}$ (II) which is known to predict complex with FolinCiocalteu reagent.

Total flavonoid content: The pharmacological activity such as antioxidant, anti-inflammatory and anticancer is well documented. ${ }^{21}$ There was a significant variation in the accumulation of total flavonoids. The amount of TFC in amla fruit with regard to the three different maturity stages was found to increase as $\mathrm{S} 3>\mathrm{S} 2>\mathrm{S} 1$. The results were similar to total phenolic content. The immature stage fruit extract showed the lower amount of flavonoid content $(8.61 \pm 0.01 \mathrm{mg} / \mathrm{gm} \mathrm{QE})$ compared to fully ripe fruit extract $(9.11 \pm 0.2 \mathrm{mg} / \mathrm{gm} \mathrm{QE})$. It might be due to condensation of different phenolic acids to complex phenolic compounds such as lignin etc. ${ }^{22}$ This result was in agreement with other authors who suggested that flavonoid content decrease with advanced maturity ${ }^{23}$. The results are tabulated in table 1 .

DPPH radical-scavenging activity: The relative antioxidant ability of $P$. emblica extract was measured by percent inhibition of $\mathrm{DPPH}^{\circ}$ and ABTS radicals. The results showed significant variation among maturity stages collected fruits extract. The DPPH free radical scavenging capacity of amla fruit extracts increased in a concentration dependent manner (Table 2).
The $80 \% \mathrm{MeOH}$ extract showed a DPPH radical scavenging activity consistent with the trends for TPC $\left(\mathrm{IC}_{50} ; 78.23,30.00,18.55 \mu \mathrm{g} / \mathrm{mL}\right.$, in immature, intermediate, and mature stage, respectively). The $\mathrm{DPPH} \cdot$ is decolorized by accepting an electron donated by an antioxidant. The reducing potential of a substrate usually depends on the concentration of reductants. ${ }^{24} \mathrm{~A}$ compound possessing radical reducing power can act as a potential antioxidant. Such compounds inhibit the formation of free radicals which are considered to play a key role in cardiovascular diseases as well as cancer. ${ }^{25,26}$

$\mathrm{ABTS}$ is a blue chromophore produced by the reaction between $\mathrm{ABTS}$ and potassium persulfate. Addition of the amla extract to this pre-formed radical cation reduced it to ABTS in a concentrationdependent manner. The results of ABTS scavenging activity were similar to DPPH assay. The $\mathrm{IC}_{50}$ values was shown positive correlation with polyphenol content of different maturity amla extracts (Table 3). The $\mathrm{IC}_{50}$ value demonstrates that the $\mathrm{S} 3$ extract is a potent antioxidant.

The results reflect that the S3 has shown almost similar antioxidant potential. These results might be due to higher amount of polyphenol and accumulation of ascorbic acid and copper and like reducing minerals. It is worth to mention here the antioxidant potential of S3 was highest. It can be justified as there is decrease in the concentration of total phenolics, and consumption of anthocyanins during maturation (S2 stage) and accumulation of higher amount of vitamin $\mathrm{C}$ in S3 stage of amla fruit. ${ }^{17}$

For determination of total antioxidant activity phosphomolybdenum assay and metal chelating activity are reported. This phosphomolybdenum assay measures the relative antioxidant ability of fruits to scavenge the radical MO (VI) as compared with a standard amount of ascorbic acid $(y=011 x-0121)$. The antioxidant activity of all the three samples/extracts was estimated using standard curve of ascorbic acid (Figure 1). This assay is an excellent tool for determining the antioxidant activity of hydrogendonating antioxidants and of chain breaking antioxidants. ${ }^{12}$

The phosphomolybdenum assay is a quantitative method to evaluate water-soluble and fat-soluble antioxidant capacity (total antioxidant capacity), in which transforming of relative free radical species MO (VI) into more stable MO (V) non-reactive products occurs.

The in antioxidant capacity of S2 during maturation might be linked to decrease in the concentration of total phenolics, and rapid consumption of anthocyanins and compositional changes as a result of fruit development (Table 4). 


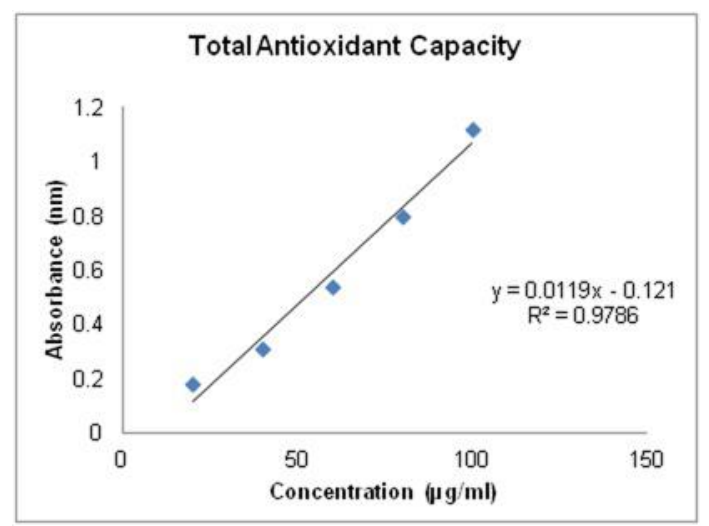

Fig 1: Total antioxidant capacity; calibration curve of ascorbic acid standard

Table 1: Extractive yield of hydroalcoholic extract, total phenolic and total flavonoid content of different maturity stages $P$. embelica fruit extract

\begin{tabular}{|c|c|c|c|c|}
\hline S. No & Amla extract & \% Extractive & $\begin{array}{c}\text { Total phenolic content } \\
\text { (mg/gm of GAE) }\end{array}$ & $\begin{array}{c}\text { Total Flavonoid } \\
\text { content (mg/gm of QE) }\end{array}$ \\
\hline 1 & $\mathrm{~S}_{1}$ Extract & $20.14 \pm 1.24$ & $78.5 \pm 0.22$ & $8.61 \pm 0.01$ \\
\hline 2 & $\mathrm{~S}_{2}$ Extract & $28.14 \pm 1.17$ & $99.8 \pm 0.18$ & $8.70 \pm 0.03$ \\
\hline 3 & $\mathrm{~S}_{3}$ Extract & $31.01 \pm 2.11$ & $105.3 \pm 0.34$ & $9.11 \pm 0.02$ \\
\hline
\end{tabular}

$n=3$; mean $\pm S D$; S1 - immature stage; S2 - intermediate stage; S3 - mature stage; GAE- Gallic acid equivalence; $\mathrm{QE}-$ Quercetin equivalence

Table 2: Free radical scavenging activity by DPPH of different maturity stages $P$. embelica fruit extract

\begin{tabular}{|c|c|c|c|c|c|c|}
\hline \multirow[b]{2}{*}{ S. no } & \multirow{2}{*}{$\begin{array}{c}\text { Gallic acid } \\
(\mu \mathrm{g} / \mathrm{ml})\end{array}$} & \multicolumn{4}{|c|}{ \% Inhibition } & \multirow{2}{*}{$\begin{array}{l}\text { Sample } \\
(\mu \mathrm{g} / \mathrm{ml})\end{array}$} \\
\hline & & Gallic acid & S1 & S2 & S3 & \\
\hline 1 & 10 & $24.34 \pm 2.11$ & $29.71 \pm 1.81$ & $46.43 \pm 2.14$ & $53.78 \pm 2.40$ & 20 \\
\hline 2 & 20 & $31.50 \pm 1.45$ & $46.54 \pm 3.65$ & $53.81 \pm 2.22$ & $54.35 \pm 2.18$ & 40 \\
\hline 3 & 30 & $37.84 \pm 0.79$ & $48.92 \pm 2.18$ & $58.67 \pm 3.17$ & $57.56 \pm 2.11$ & 60 \\
\hline 4 & 40 & $38.38 \pm 1.11$ & $51.03 \pm 2.38$ & $63.99 \pm 3.51$ & $67.50 \pm 2.46$ & 80 \\
\hline 5 & 50 & $45.41 \pm 2.81$ & $51.81 \pm 2.44$ & $69.69 \pm 2.55$ & $75.47 \pm 3.17$ & 100 \\
\hline IC 50 & & $59.63 \pm 2.45$ & $78.23 \pm 3.83$ & $30.00 \pm 1.78$ & $18.55 \pm 1.05$ & \\
\hline
\end{tabular}

Values are mean $\pm \mathrm{SD}, \mathrm{n}=3$; S1 - immature stage; S2 - intermediate stage; S3 - mature stage

Table 3: Free radical scavenging activity by ABTS of different maturity stages $P$. embelica fruit extract

\begin{tabular}{|c|c|c|c|c|c|c|}
\hline \multirow[b]{2}{*}{ S. no } & \multirow{2}{*}{$\begin{array}{c}\text { Gallic acid } \\
(\mu \mathrm{g} / \mathrm{ml})\end{array}$} & \multicolumn{4}{|c|}{ \% Inhibition } & \multirow{2}{*}{$\begin{array}{l}\text { Sample } \\
(\mu \mathrm{g} / \mathrm{ml})\end{array}$} \\
\hline & & Gallic acid & S1 & S2 & $\mathbf{S 3}$ & \\
\hline 1 & 10 & $20.80 \pm 1.02$ & $48.54 \pm 1.49$ & $44.74 \pm 2.60$ & $24.45 \pm 1.84$ & 20 \\
\hline 2 & 20 & $24.58 \pm 1.54$ & $51.41 \pm 1.67$ & $49.42 \pm 2.41$ & $38.45 \pm 1.94$ & 40 \\
\hline 3 & 30 & $39.89 \pm 0.87$ & $62.76 \pm 1.89$ & $53.45 \pm 2.12$ & $49.74 \pm 2.35$ & 60 \\
\hline 4 & 40 & $47.12 \pm 1.87$ & $71.21 \pm 2.17$ & $58.74 \pm 3.34$ & $56.61 \pm 2.61$ & 80 \\
\hline 5 & 50 & $69.03 \pm 1.64$ & $72.44 \pm 3.14$ & $65.78 \pm 3.74$ & $61.54 \pm 3.22$ & 100 \\
\hline \multicolumn{2}{|c|}{$\mathrm{IC}_{50}(\mu \mathrm{g} / \mathrm{ml})$} & $38.17 \pm 1.04$ & $26.66 \pm 1.13$ & $42.80 \pm 3.68$ & $68.44 \pm 3.45$ & \\
\hline
\end{tabular}

Values are mean $\pm \mathrm{SD}, \mathrm{n}=3$; S1 - immature stage; S2 - intermediate stage; S3 - mature stage

Table 4: Total Antioxidant capacity of different maturity stages $P$. embelica fruit extract

\begin{tabular}{|c|c|c|}
\hline S. No & $\begin{array}{c}\text { Amla } \\
\text { Extract }\end{array}$ & $\begin{array}{c}\text { Total Antioxidant } \\
\text { capacity }(\mathbf{m g} / \mathbf{g m} \text { AAE) }\end{array}$ \\
\hline 1 & S1 Extract & $8.84 \pm 0.34$ \\
\hline 2 & S2 Extract & $7.48 \pm 0.57$ \\
\hline 3 & S3 Extract & $10.75 \pm 0.32$ \\
\hline
\end{tabular}

Values are mean $\pm \mathrm{SD}, \mathrm{n}=3 ; \mathrm{S} 1$ - immature stage; $\mathrm{S} 2$ intermediate stage; S3 - mature stage; AAE - Ascorbic acid equivalent
Conclusion

The present study is the first to evaluate the antioxidant property at different ripening stages of maturity. Based on the present results, it can conclude that fruit ripening stage had profound effects on polyphenolic contents and antioxidant activity of amla fruit. Considering its high content of antioxidants, amla fruit might be considered as an interesting food to improve the antioxidant status and to obtain the maximum nutritional and medicinal benefits of such 
fruits. Further studies are needed in order to understand the impact on the nutritional values of $P$. emblica $L$. of various environmental conditions during the growing period and after harvest.

\section{References}

1. Astley SB. Dietary antioxidants - past, present and future? Trends in Food Science \& Technology. 2003;14(3):93-8.

2. Chung K-T, Wong TY, Wei C-I, Huang Y-W, Lin Y. Tannins and human health: a review. Critical reviews in food science and nutrition. 1998;38(6):421-64.

3. Ruiz-Terán F, Medrano-Martínez A, Navarro-Ocaña A. Antioxidant and free radical scavenging activities of plant extracts used in traditional medicine in Mexico. African Journal of Biotechnology. 2008;7(12).

4. Chirinos R, Pedreschi R, Rogez H, Larondelle Y, Campos D. Phenolic compound contents and antioxidant activity in plants with nutritional and/or medicinal properties from the Peruvian Andean region. Industrial Crops and Products. 2013;47:145-52.

5. Ilahy R, Hdider C, Lenucci MS, Tlili I, Dalessandro G. Antioxidant activity and bioactive compound changes during fruit ripening of high-lycopene tomato cultivars. Journal of Food Composition and Analysis. 2011;24(45):588-95.

6. Villa-Rodriguez JA, Molina-Corral FJ, Ayala-Zavala JF, Olivas GI, Gonzalez-Aguilar GA. Effect of maturity stage on the content of fatty acids and antioxidant activity of 'Hass' avocado. Food Research International. 2011;44(5):1231-7.

7. Siddiqui MW, Momin CM, Acharya P, Kabir J, Debnath MK, Dhua R. Dynamics of changes in bioactive molecules and antioxidant potential of Capsicum chinense Jacq. cv. Habanero at nine maturity stages. Acta physiologiae plantarum. 2013;35(4):1141-8.

8. Sairam K, Rao CV, Babu MD, Kumar KV, Agrawal V, Goel RK. Antiulcerogenic effect of methanolic extract of Emblica officinalis: an experimental study. Journal of Ethnopharmacology. 2002;82(1):1-9.

9. Bhandari P, Kamdod M. Emblica officinalis (Amla): A review of potential therapeutic applications. International Journal of Green Pharmacy. 2012;6(4):257.

10. Harborne AJ. Phytochemical methods a guide to modern techniques of plant analysis: springer science $\&$ business media; 1998.

11. Kokate CK. Practical pharmacognosy, . New Delhi: VallabhPrakashan,; 1994. 15-30 p.

12. Kalaskar MG, Surana SJ. Free radical scavenging, immunomodulatory activity and chemical composition of Luffa acutangula var: amara (Cucurbitaceae) pericarp. Journal of the Chilean Chemical Society. 2014:59(1):2299-302.

13. Jamkhande PG, Wattamwar AS, Kankudte AD, Tidke PS, Kalaskar MG. Assessment of Annona reticulata Linn. leaves fractions for invitro antioxidative effect and antimicrobial potential against standard human pathogenic strains. Alexandria Journal of Medicine. 2016;52(1):19-25.

14. Fellegrini N, Ke R, Yang M, Rice-Evans C. [34] Screening of dietary carotenoids and carotenoid-rich fruit extracts for antioxidant activities applying 2, 2'-azinobis (3-ethylenebenzothiazoline-6-sulfonic acid radical cation decolorization assay. Methods in enzymology. 299: Elsevier;1999. p. 379-89.

15. Ghasemzadeh A, Jaafar HZ, Rahmat A. Effects of solvent type on phenolics and flavonoids content and antioxidant activities in two varieties of young ginger (Zingiber officinale Roscoe) extracts. Journal of medicinal plants research. 2011;5(7):1147-54.

16. Halvorsen BL, Holte K, Myhrstad MC, Barikmo I, Hvattum E, Remberg SF, et al. A systematic screening of total antioxidants in dietary plants. The Journal of nutrition. 2002;132(3):461-71.

17. Bashir HA, Abu-Goukh A-BA. Compositional changes during guava fruit ripening. Food Chemistry. 2003;80(4):557-63.

18. Vendramini AL, Trugo LC. Chemical composition of acerola fruit (Malpighia punicifolia L.) at three stages of maturity. Food Chemistry. 2000;71(2):195-8.

19. Parr AJ, Bolwell GP. Phenols in the plant and in man. The potential for possible nutritional enhancement of the diet by modifying the phenols content or profile. Journal of the Science of Food and Agriculture. 2000;80(7):9851012.

20. Lewak S. Determination of the degree of polymerization of leucoanthocyanidins. Phytochemistry. 1968;7(4):6657.

21. Kang J, Li Z, Wu T, Jensen GS, Schauss AG, Wu X. Anti-oxidant capacities of flavonoid compounds isolated from acai pulp (Euterpe oleracea Mart.). Food Chemistry. 2010;122(3):610-7.

22. Ben Ahmed C, Ben Rouina B, Sensoy S, Boukhriss M. Saline water irrigation effects on fruit development, quality, and phenolic composition of virgin olive oils, $\mathrm{Cv}$. Chemlali. Journal of agricultural and food chemistry. 2009;57(7):2803-11.

23. Menichini F, Tundis R, Bonesi M, Loizzo MR, Conforti F, Statti G, et al. The influence of fruit ripening on the phytochemical content and biological activity of Capsicum chinense Jacq. cv Habanero. Food Chemistry. 2009;114(2):553-60.

24. Duh P-D, Tu Y-Y, Yen G-C. Antioxidant activity of water extract of Harng Jyur (Chrysanthemum morifolium Ramat). LWT-Food Science and Technology. 1999;32(5):269-77.

25. Valko M, Izakovic M, Mazur M, Rhodes CJ, Telser J. Role of oxygen radicals in DNA damage and cancer incidence. Molecular and cellular biochemistry. 2004;266(1-2):37-56.

26. Nakabeppu Y, Sakumi K, Sakamoto K, Tsuchimoto D, Tsuzuki T, Nakatsu Y. Mutagenesis and carcinogenesis caused by the oxidation of nucleic acids. Biological chemistry. 2006;387(4):373-9. 